\title{
Earthing Transformer to Support the Normal Operation of the Power System at Failure of a Protection System
}

\author{
Yousuf Mohammad Younes \\ Department of Electrical Engineering, Collage of \\ Engineering, Mosul University, Mosul, Iraq
}

\author{
Abdul Ghani A. A, PhD \\ Department of Electrical Engineering Collage of \\ Engineering, Mosul University, Mosul, Iraq
}

\begin{abstract}
This paper dealt with possible type of contingencies which occurred in several power systems in the world which related to maloperation of a protection system for a line or a transformer and their consequences related to overloading another branches and hence, lead to cascading outages. To minimize the fault level and prevent the cascading outages and hence, prevent partial (brownout) or complete (blackout) collapse of the system an earthing (grounding) transformer is used on both sides of the faulted line . This suggested solution to able the system to be a secure system against maloperation of a protective system. This paper offers the simulation results of the IEEE 14 Bus system which represented in MATLAB at off line security analysis.
\end{abstract}

\section{Keywords}

Earthing Transformer, Maloperation of relay, Static Security, Cascading outages.

\section{INTRODUCTION}

Power system security opened new horizons in planning, design and operation stages to deliver all the connected loads at different situations even at worst conditions at which the system may suffer from them, as far as possible, without violating any operational constraints which may lead to shed the service to the load/loads by withstanding these disturbances [1,2]. To withstand the consequences of severe contingencies, the power system must have the ability to do that, where this ability can be achieved by secure system which gives the power system a minimal probability of blackout and equipment damage, [3,4].This can only be achieved by selecting a group of severe contingencies that may be exposed to the power system during operation at future online operation. This paper dealt with the possibility of failure of a relay protection in the sense of fault or issuing the trip signal to the circuit breaker without fault as well as the magnitudes of transient over voltages when restriking ground faults occur, limit the current during line to ground faults, permit the circulation of unbalanced load current in the neutral and permit the connection of phase-to-neutral loads possibility of failure circuit breaker to disconnect and isolate the fault part of the system which may lead to override the thermal limits of another branches and the cascading outages that resulting from this mal operation of a relay or a circuit breaker, which may lead to split the system into more than isolated region.

\section{THERMAL PERFORMANCE INDEX}

$\left(\mathbf{P I}_{\mathrm{T}}\right)$

Thermal performance index $\left(\mathrm{PI}_{\mathrm{T}}\right)$ defines a set of most possible harmful contingencies that actually leads to the violation of the operational limits to give planners, operators a very quickly list of "worst case" contingencies, then the operator is able to estimate between the secure and non-secure cases where a higher index value means a higher severity degree [5,6,7]. Computation of $\mathrm{PI}_{\mathrm{T}}$ it is required to check the active power limits of all branches in the power system against their respective limits for each outage tested. The $\mathrm{PI}_{\mathrm{T}}$ will be less than 1 if active power flow is within permissible thermal limit, and it will be large than 1 if any branch is overloaded $[8,9]$.

$P I_{T} \quad=\frac{P_{i}}{P_{i}^{\max }}$

Where,

$\mathrm{P}_{\mathrm{i}}$ : active power flow in line $\mathrm{i}$,

$\mathrm{P}_{\mathrm{i}}^{\max }$ : maximum active power flow (thermal limit) in line $\mathrm{i}$ /the MW capacity of line i.

\section{EARTHING TRANSFORMER}

A grounding transformer or earthing transformer is a type of auxiliary transformer used in three phase electric power system to provide an easy path to ground fault current during line-to-ground faults, ground the system. Limit the

when desired. To protect a system against earth fault currents, earthing transformer is used to pass ground current during ground faults to return path for earth current, as shown in fig (1), $[10,11]$.

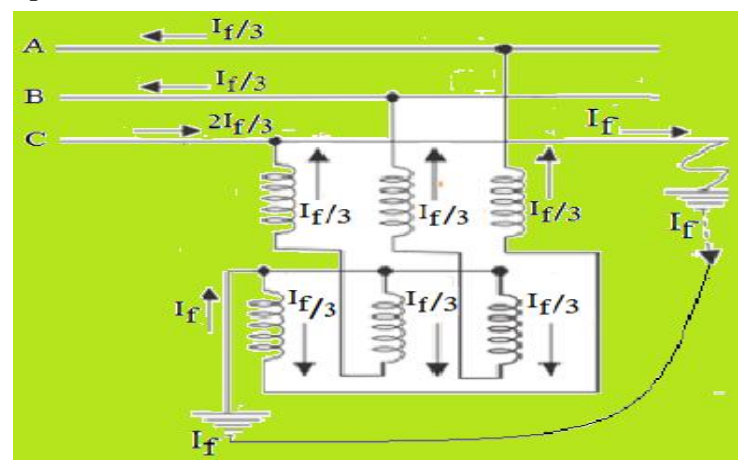

Fig 1: Earth fault current when single line to ground fault occurs on any has of the system. 
Two types of grounding transformer are in general used:

1) A Zig-Zag transformer,
2) A Wye-Delta transformer, Fig. (2) shows the two most common grounding transformer

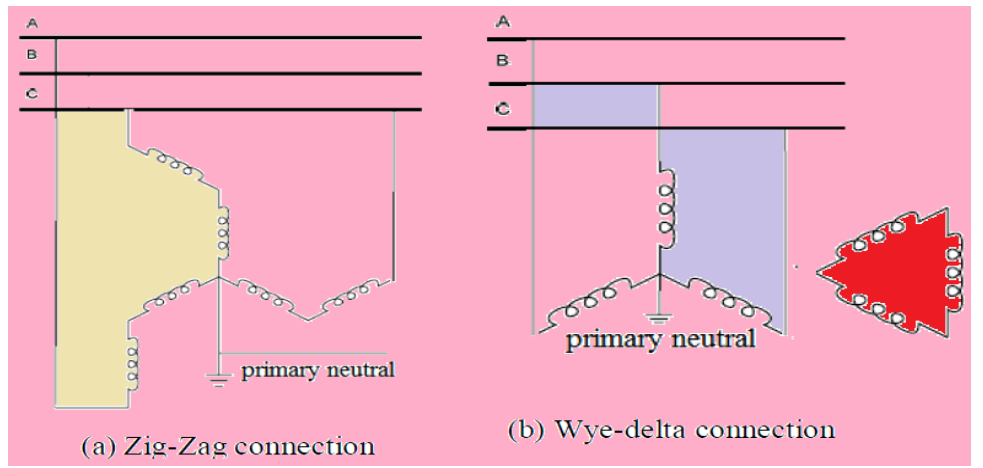

Fig 2: Grounding transformer connections.

The impedance of all types of grounding transformers to normal three phase currents is high so that when there is no ground fault and no unbalanced phase-to-neutral load on the system, only a small magnetizing current flows in the transformer windings. Most grounding transformers are designed to carry their ground current for a limited time only, such as 10 seconds to 1 minute $[10,11]$.

\section{THE RESULTS OF PROTECTION}

\section{FAIL AT A BRANCH CONTINGENCY}

This study deals with the failed of distance protection for transmission line or differential protection for tap transformer, or maybe there is no problem in protection system and the trip signal is reach to circuit breaker (C.B), but C.B is failed to open the faulted branch.The consequences of this deteriorating is result to overload of another branches plus drop of buses voltages leading the system to an emergency state or in extriems state. The security system is failed and the system suffers from brownout or even blackout conditionsSo, it is needed to take some suitable actions to come back the system to secure state or in worst solution into alert state to maintain the continuity of supplying the loads.The S.C fault (Line to Ground fault) is achieved for all branches of IEEE 14 bus model that simulated and the figure (3) shows the branches that suffer from fail the protection systems or C.B's.

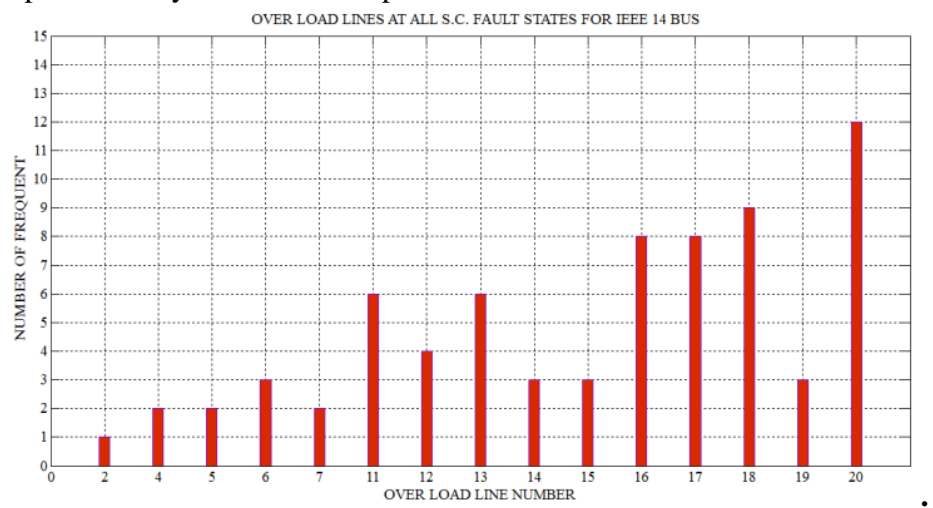

Fig 3: Over load branches as a consequences of failed protection systems for all S.C. fault states

The above figure, gives the over load branches and number of their frequent for all S.C fault states that studied in the tested model. Not all these branches lead to islanding the loads when these branches are outage. After simulation all studied states at fault and the consequences of fail protection systems conditions, it is clear that the following branches lead to isolation some loads buses, when any one of them is outage as a result of maloperation of the protection system for faulted branch, as shown in the table (1), and the load buses that suffer from these deteriorates are shown in the following table (2).
Table 1: Identify the line outage that lead to in extriems state.

\begin{tabular}{|c|c|c|c|}
\hline $\begin{array}{c}\text { Number } \\
\text { of } \\
\text { branch }\end{array}$ & $\begin{array}{c}\text { From } \\
\text { Bus }\end{array}$ & $\begin{array}{c}\text { To } \\
\text { Bus }\end{array}$ & $\begin{array}{c}\text { Island the load bus } \\
\text { when overload line is } \\
\text { outage as a result of } \\
\text { consequence of relay } \\
\text { or C.B. failed }\end{array}$ \\
\hline 15 & 7 & 9 & YES \\
\hline 16 & 9 & 10 & YES \\
\hline 17 & 9 & 14 & YES \\
\hline 18 & 10 & 11 & YES \\
\hline 19 & 12 & 13 & YES \\
\hline 20 & 13 & 14 & YES \\
\hline
\end{tabular}


Table 2: Load buses that suffer from danger of islanding.

\begin{tabular}{|c|c|c|}
\hline LOAD BUS & VALUE of ACTIVE LOAD in p.u & VALUE of REACTIVE LOAD in p.u. \\
\hline 9 & 0.166 & 0.295 \\
\hline 10 & 0.058 & 0.09 \\
\hline 11 & 0.018 & 0.035 \\
\hline 12 & 0.016 & 0.061 \\
\hline 13 & 0.058 & 0.135 \\
\hline 14 & 0.05 & 0.149 \\
\hline
\end{tabular}

5. AS A SAMPLES, STUDY OF

DETERIORATE THE FAIL DISTANCE RELAY OR C.B FOR FAULTED LINES

\section{9-14 AND LINE 13-14 RESPECTIVEL}

It is assumed that a line to ground fault is happen at the middle of line 9-14, as shown in figure (4). Assuming that a protection system for this line is failed and this line doesn't outage, so some another branches are overloaded and this action lead to tripping these overloaded branches.

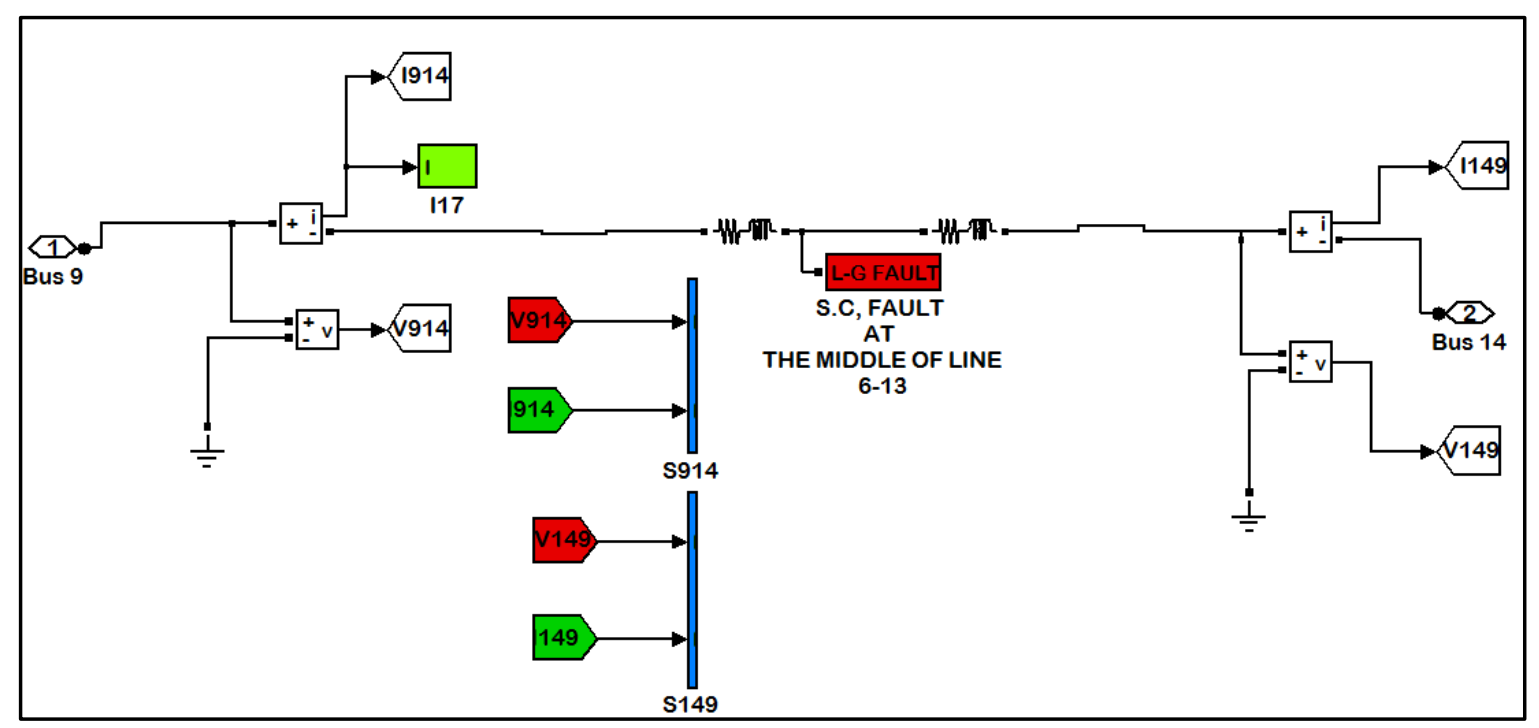

Fig 4: L-G fault at the middle 9-14.

Table 3: Overloaded lines and deteriorate voltage bus.

\begin{tabular}{|c|c|c|c|c|c|}
\hline $\begin{array}{c}\text { Line } \\
\text { number }\end{array}$ & From bus & To bus & $\begin{array}{c}\text { Percentage of overload active } \\
\text { power }\end{array}$ & $\begin{array}{c}\text { Bus number } \\
\text { Voltage value in } \\
\text { p.u. }\end{array}$ \\
\hline 11 & 6 & 11 & 111.4 & 4 & 0.8837 \\
\hline 12 & 6 & 12 & 120.7 & 5 & 0.9168 \\
\hline 13 & 6 & 13 & 130 & 10.7716 \\
\hline 15 & 7 & 9 & 112.1 & 11 & 0.626 \\
\hline 16 & 9 & 10 & 175 & 12 & 0.8023 \\
\hline 18 & 10 & 11 & 226.2 & 13 & 0.9033 \\
\hline 20 & 13 & 14 & 299 & 10.8131 \\
\hline
\end{tabular}

From above table, the all above lines are disconnected, but disconnect of lines $15,16,18$ and 20 lead to isolate the loads $9,10,11$ and 14and the system enters to in-extriems state. While for a line to ground fault at the middle of line 13-14, as shown results in table (4). Assuming that a protection system for this line is failed and this line doesn't outage, so some another branches are overloaded and this action lead to tripping these overloaded branches. 
Table 4: Overloaded lines at failed protection at line 13-14

\begin{tabular}{|c|c|c|c|}
\hline $\begin{array}{c}\text { Line } \\
\text { number }\end{array}$ & From bus & To bus & Percentage of overload active power \\
\hline 12 & 6 & 12 & 217.6 \\
\hline 13 & 6 & 13 & 245.2 \\
\hline 17 & 9 & 14 & 323.3 \\
\hline 18 & 10 & 11 & 133.7 \\
\hline 19 & 12 & 13 & 489.5 \\
\hline
\end{tabular}

From above table, the all above lines are disconnected, but when any one of lines 17 and 19 or all, the loads 12, 13 and14 are isolated then the system enters to in-extriems state. As it is known, at in-extriems state, the system subject to partial or complete blackout, so, it is necessary to take correction actions to return the system to secure or alert state. If the control actions aren't sufficient and aren't able to do this, the system goes to restorative state. It is noticed, that the big problem here, is overloaded lines and penalties of their tripping. So there are some suggestions to save the system from its deteriorates, with know that the shunt compensation and tap transformers here aren't able to survive the system. So, some processes are done, to save what is possible to save it, as shown in following tries.

\section{ADDING AN EARTH TRANSFORMER AT BOTH SIDES OF FAULTED LINE 9-14}

When adding an earthing transformer on each side of line 914 (L17), as shown in figure (5), the minimum voltage is 0.96 p.u., the heavy loaded branches became safe from disconnecting, faulted line became safe from damage as shown in figure (6).

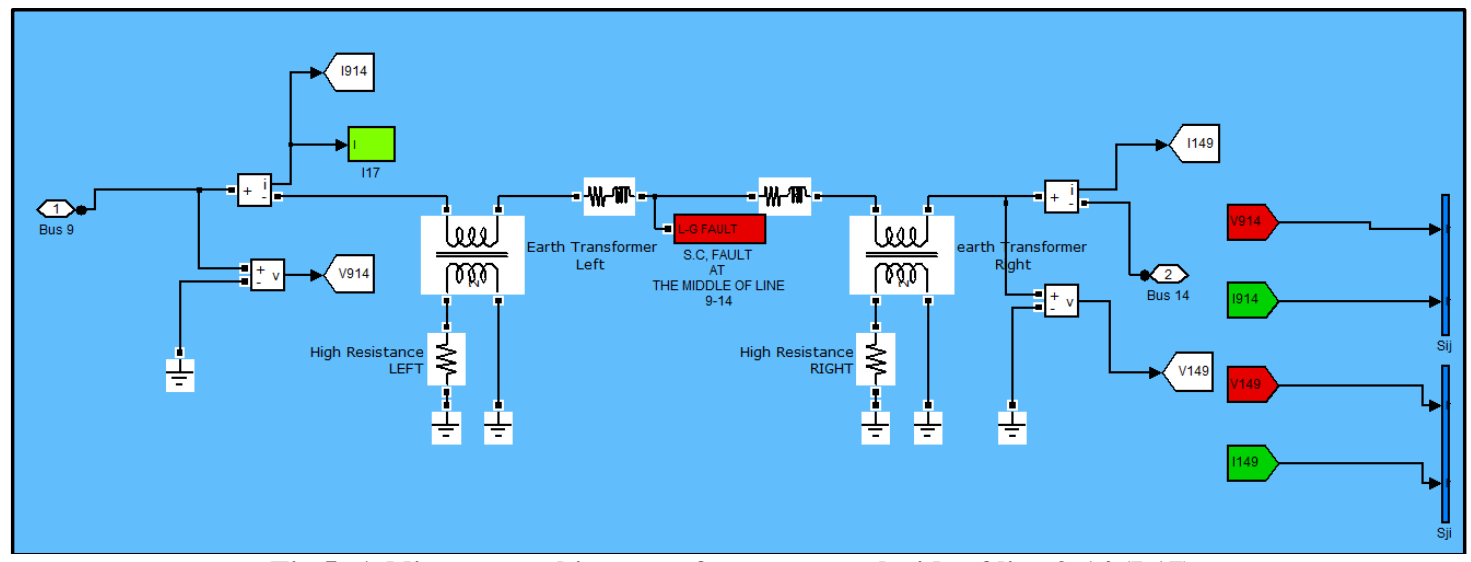

Fig 5: Adding an earthing transformer on each side of line 9-14 (L17).

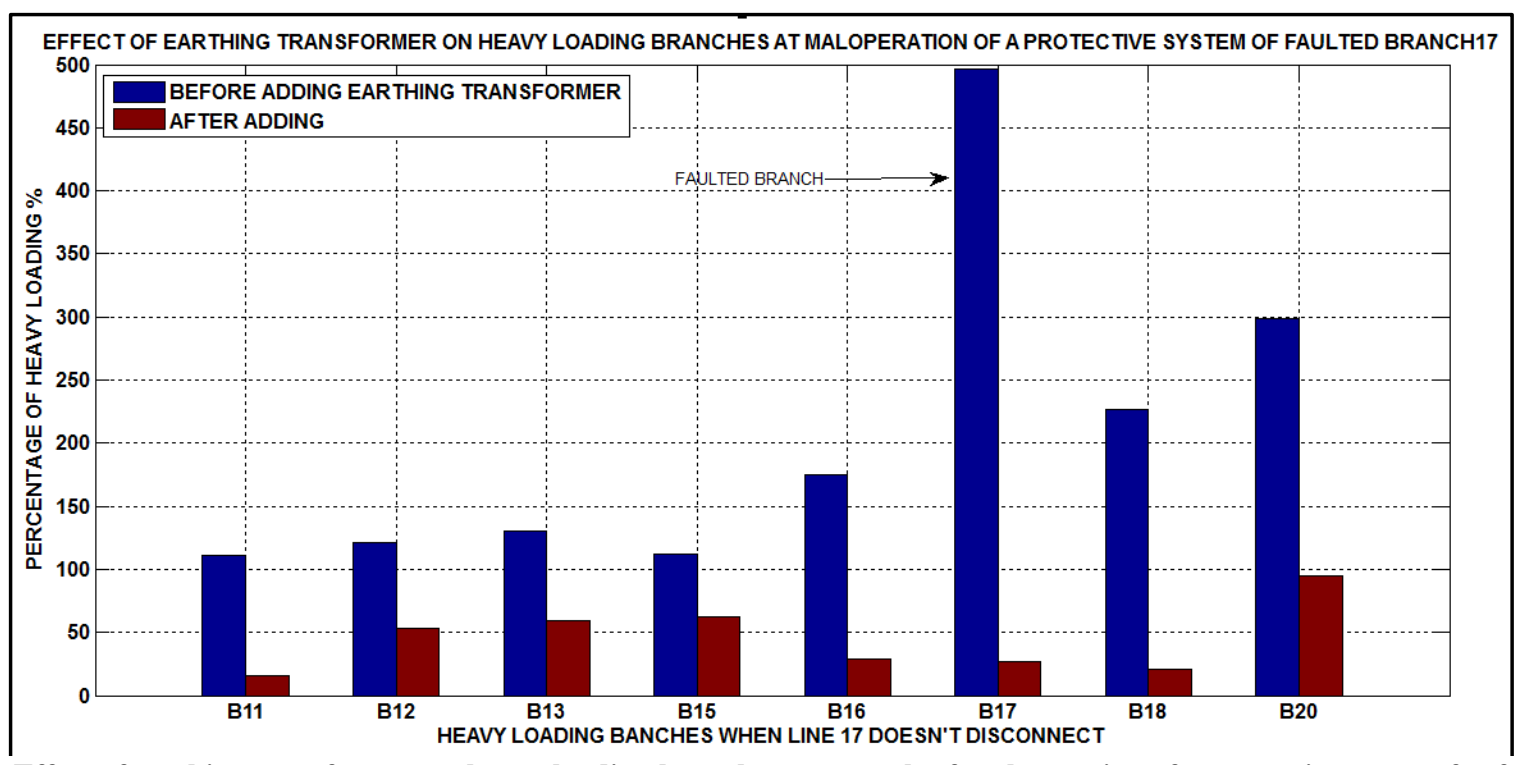

Fig 6: Effect of earthing transformer on heavy loading branches as a result of maloperation of a protective system for faulted line 17. 
When adding an earthing transformer on each side of line 1314 (L20), as shown in figure (7), the minimum voltage is 0.97 p.u., the heavy loaded branches became safe from disconnecting, faulted line became safe from damage as shown in figure (8).

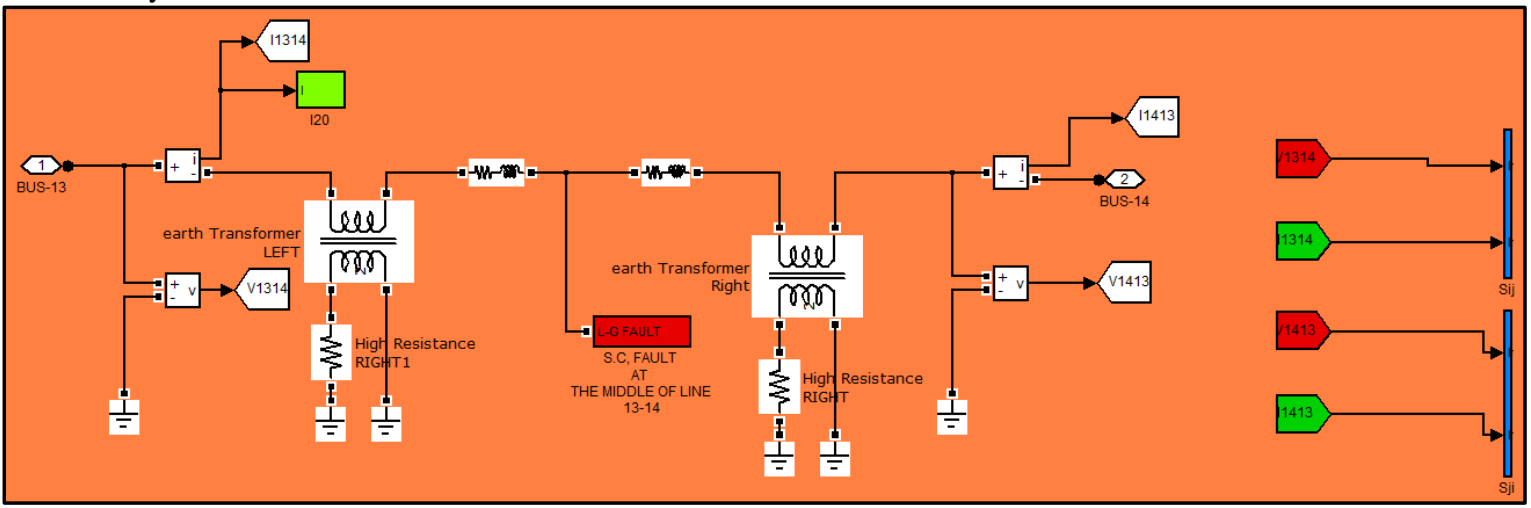

Fig 7: Adding an earthing transformer on each side of line 13-14 (L20).

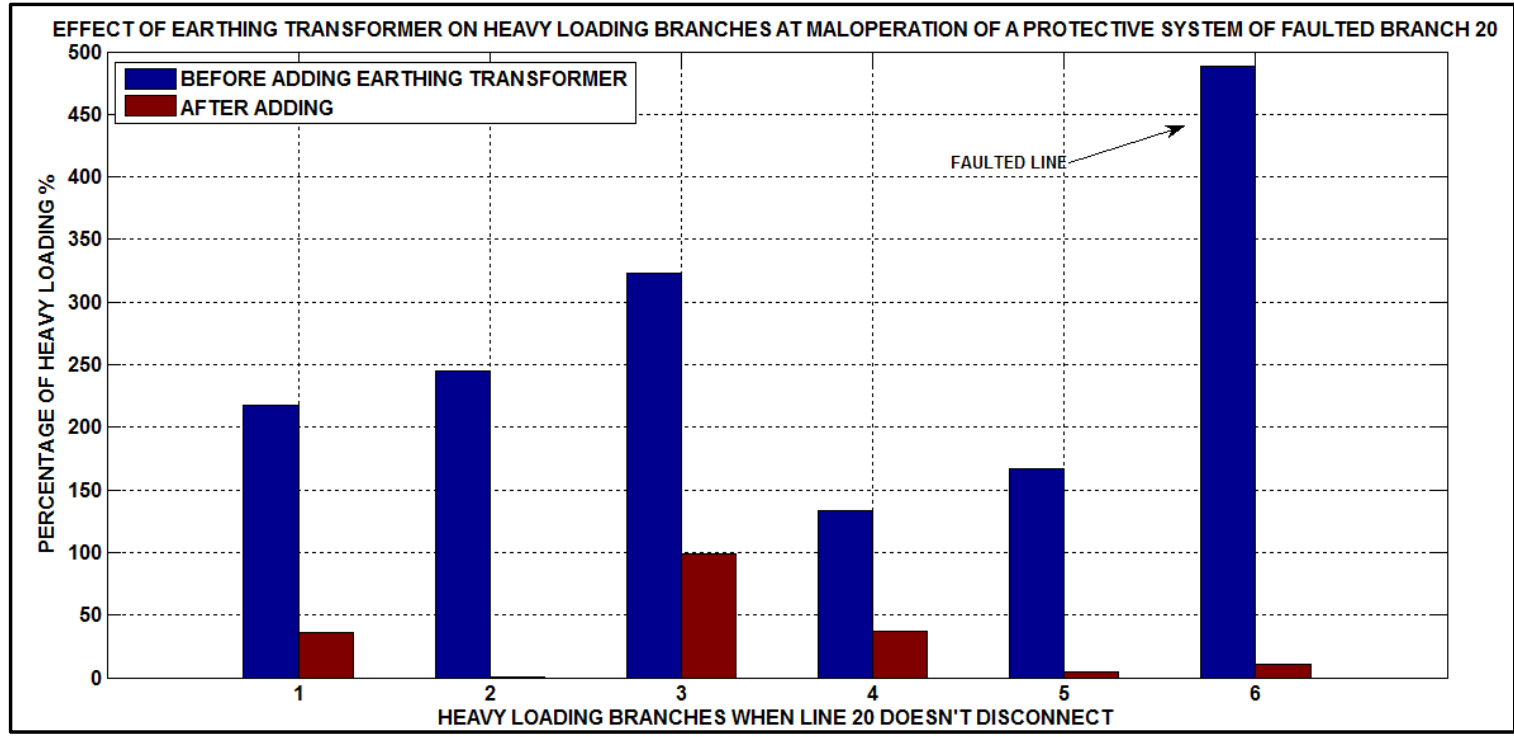

Fig 8: Effect of earthing transformer on heavy loading branches as a result of maloperation of a protective system for faulted line 20

\section{CONCLUSION}

For maloperation of a protection relay or C.B., to treat the heavy loading problem of some healthy branches, decrease the fault level of faulted line and prevent damage of faulted branch, an earthing transformer with high resistance connect at the secondary side of it is used. The using of the earth transformer is very amazement and not expected because it had achieved the following results:

a- Decrease the heavy loading levels of healthy branches into acceptable levels,

b- Decrease the fault level of faulted branch into acceptable level,

c- Increase the low voltages levels of buses into permissible levels.

d- Save the faulted branch and its accessories from damage.

\section{REFERENCES}

[1] Pudi Sekhar, January, 2016. "Assessment and Enhancement of Power System Security using Soft Computing and Data Mining Approaches" Ph.D. Thesis, National Institute of Technology Rourkela.
[2] S. Ravindra, V. C. Veera Reddy and S. Sivanagaraju, January 2015. "Power System Severity Analysis under Generator Outage Condition", International Journal of Advanced Research in Electrical, Electronics and Instrumentation Engineering, Vol. 4, Issue 1.

[3] Kip Morison, Lei Wang, and Prabha Kundur, October 2004. "Power System Security Assessment", IEEE power and energy magazine.

[4] S. Kalyani, October 2010. "A Unified Approach for Security Assessment of Power Systems Using Pattern Classifiers", Ph.D. Thesis, Department of Electrical Engineering Indian Institute of Technology Madras, India.

[5] Rohini G D, B Kantharaj and R D Satyanarayana Rao, May-June 2015. "Transmission Line Contingency Analysis in Power system using Fast Decoupled Method for IEEE-14 and IEEE-30 bus Test system", International Journal of Engineering Technology and Management (IJETM), Volume 2, Issue 3.

[6] Amit Kumar Roy, JULY 2011. "Contingency Analysis in Power System”, M.Sc.Thesis, Thapar University, Patiala. 
[7] Pritirekha Naik, May, 2014. "Power System Contingency Using Newton Raphson Load Flow Method and its Prediction Using Soft Computing Techniques" M.Sc.Thesis, Department of Electrical Engineering National Institute of Technology Rourkela.

[8] Timothy Allen Ernster, August, 2012. "Power System Vulnerability Analysis A Centrality Based Approach Utilizing Limited Information" , M.Sc.Thesis, Washington State University, School of Electrical Engineering and Computer Science.
[9] X.-F. Wang et al., 2008. "Modern Power Systems Analysis: Chapter 2

[10] Nashiren.F. Mailah and Senan M. Bashi,2009 "Single Phase Unified Power Flow Controller (UPFC): Simulation and Construction" , European Journal of Scientific Research,Vol.30 No.4.

[11] Kassim Rasheed Hameed, September 2015. "Zig-Zag Grounding Transformer Modeling For Zero-Sequence Impedance Calculation Using Finite Element Method", Diyala Journal of Engineering Sciences, Vol. 08, No. 06 , pp. 36- 78 . 